\title{
ARCHITECTURAL PRESERVATION INTERNSHIP REPORT Grand TETON NATIONAL PARK
}

\author{
CAROLINE ENGEL \\ UNIVERSITY OF EDINBURGH $\uparrow$ EDINBURGH UK
}

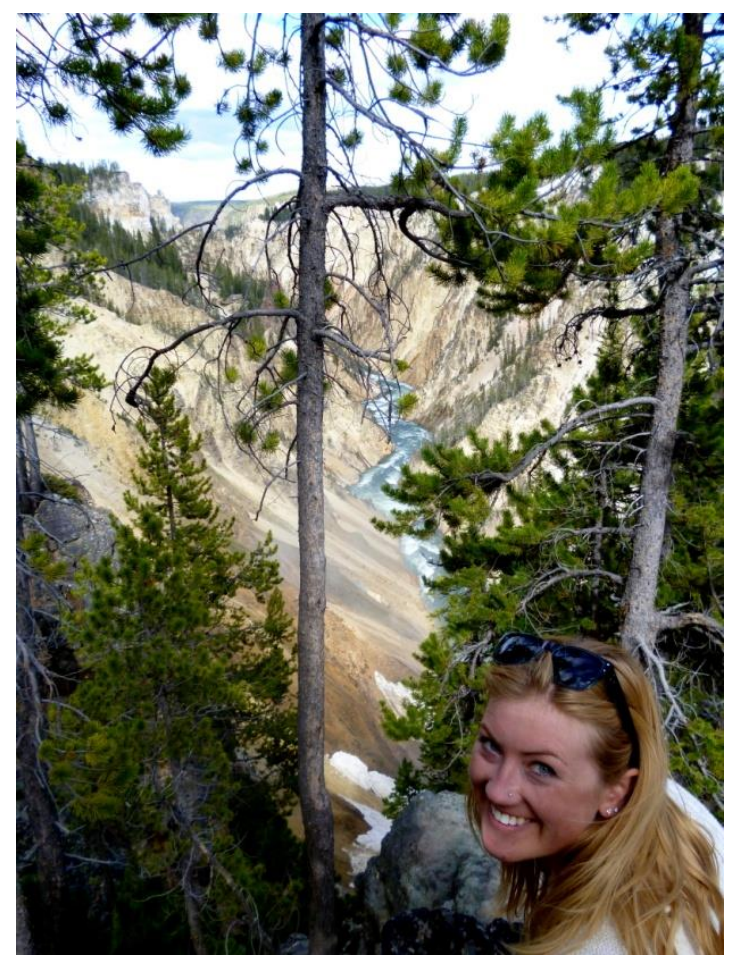

\section{$\uparrow \quad$ AbSTRACT}

As an architectural preservation intern at the Grand Teton National Park, I worked on a number of projects over the summer of 2012. The primary research project that spanned the two months was an investigation into the history of the Upper Granite Patrol Cabin. Questions had been raised by my supervisors Katherine Longfield and Betsy Engel as to what purpose the original cabin had been built, with reason to believe it may have been built as a poacher's cabin. Using resources within the GTNP, the Jackson Hole Historical Society, and research on similar building types, I determined that the cabin was not likely to be a poacher's cabin, but was most likely to be an early ranger's patrol cabin, built before the CCC and the standardization of park structures.

While the Upper Granite research project spanned the length of my internship, I worked on a number of shorter projects along the way. One of the most interesting projects was the week-long restoration of a cabin at the BarBC Ranch. Working with a group of volunteers from Wisconsin, I assisted Harrison with the direction of the project and helped the volunteers with preservation skills. The project was hands-on and many of the volunteers had never 
worked on historic buildings, but they were all very passionate and willing to learn. It is amazing what can be accomplished with a group of volunteer labourers in the short span of a week. The dilapidated cabin was rebuilt in its original form from the ground up, reusing as much original material as possible. For another cabin at the Bar BC Ranch, I worked with Katherine to design a workable green roof plan that was both simple in construction and historically sensitive, and one that would hold up in a Wyoming winter. A volunteer group constructed the green roof a week or so after I left, so I will have to enquire on its condition next summer.

An ongoing project that I picked up once I arrived was the Grand Teton National Park smart phone app project. The app had been programmed by a graduate student in the preceding year, but the app was still missing data about historical sites within the park. Working my way along the roads throughout the park, I wrote concise histories of all the major historic sites that visitors may stop at. For Mormon Row, I wrote a walking guide for visitors to access, with numerous points to access the history about the place, people and way of life as they walk along the road. In a similar fashion, I also wrote a walking tour for the historic sites around Menor's Ferry.

A number of sites within the Grand Teton National Park needed National Register Nominations prepared for them. I wasn't able to get through as many as I had hoped, but I did proofread and finish the nomination for the Jenny Lake Lodge, and I compiled and wrote the remaining portions for the Menor's Ferry and Colter Bay nominations. Some smaller projects included photographing all the structures on Mormon Row, and a few others throughout the park, and organising the photograph files within the system.

My time flew by while working with the Grand Teton National Park. I found the work both interesting, and challenging at times, but always enjoyable. It will be hard to find a better place of employment. I am extremely grateful for the opportunity. 